\title{
Long-Term Results of Coronary Artery Bypass Grafting in Patients With Left Ventricular Dysfunction
}

\author{
Mohamed A. Soliman Hamad, MD, M. Erwin S. H. Tan, MD, PhD, \\ Albert H. M. van Straten, MD, André A. J. van Zundert, MD, PhD, \\ and Jacques P. A. M. Schönberger, MD, PhD
}

Departments of Cardiothoracic Surgery and Anaesthesiology, Catharina Hospital, Eindhoven, the Netherlands

Background. In this prospective study, we investigated the determinants of long-term outcome, symptoms, and left ventricular function after coronary artery bypass grafting in patients with a moderate to severely decreased left ventricular ejection fraction.

Methods. Between 1997 and 1998, 75 consecutive patients with moderate to severe left ventricular dysfunction underwent coronary artery bypass grafting procedures. The operative mortality rate was $4.0 \%$, and the 72 survivors were monitored for 8 years. The end points were mortality, symptomatic status (New York Heart Association [NYHA] functional class), and left ventricular function.

Results. The total survival rate after 8 years was $89.3 \%$. During follow-up, 8 patients died. Death was attributed to a cardiac cause in 5 patients and to a noncardiac cause in 3. There was no statistically significant difference between preoperative and late postoperative NYHA functional class, despite a statistically significant im-

$\mathrm{T}^{\mathrm{s}}$ he number of patients with advanced left ventricular dysfunction who undergo coronary artery bypass grafting (CABG) has increased in the past few years [1]. Although the recovery of impaired myocardial function has been shown to occur after CABG, contractile left ventricular dysfunction remains a negative determinant of postoperative outcome [2]. Impaired left ventricular function, which has been shown to be an independent predictor of operative mortality in patients who undergo CABG [3], can also lead to low cardiac output and a high postoperative mortality rate [4]. Many patients with impaired left ventricular function require inotropic or mechanical support for hours to days after surgery [4]. In the last decade, an improvement in surgical techniques and perioperative management has led to a better postoperative course and decreased postoperative mortality and morbidity rates in this high-risk group of patients $[5,6]$.

Although surgical revascularization may be successful in the short term, little is known about the long-term

Accepted for publication Sept 10, 2007.

Address correspondence to Dr Soliman Hamad, Department of Cardiothoracic Surgery, Catharina Hospital, Michelangelolaan 2, Postbus 1350, Eindhoven, 5602 ZA, the Netherlands; e-mail: aasmsn@cze.nl. provement that persisted for up to 4 years after CABG. The results of echocardiography showed a statistically significant improvement in the left ventricular ejection fraction (from $0.322 \pm 0.06$ preoperatively to $0.463 \pm 0.02$ at follow-up, $p<0.001)$. Multivariate analysis revealed that the left ventricular end-systolic volume index, the presence of angina pectoris, and absence of symptoms of congestive heart failure were preoperative indicators of freedom from heart failure after coronary operations $(p<$ 0.05).

Conclusions. Coronary artery bypass grafting for patients with moderate-to-severe left ventricular dysfunction is associated with acceptable long-term results. The left ventricular end-systolic volume index is a simple noninvasive method to aid in the preoperative decision making in such patients.

(Ann Thorac Surg 2008;85:488-93) (C) 2008 by The Society of Thoracic Surgeons

results of successful CABG in patients with coronary artery disease and left ventricular dysfunction [7]. However, certain high-risk subgroups of patients remain at increased risk for complications and death despite progressive advances in perioperative care and myocardial protection [8]. We prospectively studied 75 patients with moderate to severe left ventricular dysfunction who underwent primary elective CABG between 1997 and 1999. Immediate and short-term results have shown the safety of CABG in this group of patients [9]. Our study presents the long-term outcome in this group of patients with regard to clinical status and predictors of freedom from congestive heart failure (CHF).

\section{Patients and Methods}

Between July 1997 and March 1999, 75 consecutive patients with impaired left ventricular function who underwent CABG in Catharina Hospital, Eindhoven, the Netherlands, were enrolled in this prospective study of long-term outcome. This study was approved by the Medico-Ethical Review Committee, and an informed consent was signed by every patient before enrollment. The inclusion criteria 
Table 1. Preoperative Characteristics of Patients

\begin{tabular}{lc}
\hline Patients (n) & 75 \\
\hline Age, y (mean \pm SD) & $64 \pm 13$ \\
Male/female ratio & $22 / 3$ \\
NYHA functional class, No. & \\
I & 15 \\
II & 13 \\
III & 19 \\
IV & 28 \\
Preoperative mitral regurgitation, No. & \\
No & 46 \\
Trivial & 22 \\
Mild & 7 \\
Preoperative Q-wave MI (>30 days), & 46 \\
$\quad$ No. & \\
Primary indication for operation, No. & 18 \\
Heart failure & 34 \\
Angina & 10 \\
Both & 2 \\
Ventricular arrhythmia, No. & 11 \\
Critical anatomy, No. & \\
LVESVI (mL/m ${ }^{2}$ ) & \\
Mean \pm SD (range) & 78.4 \\
Median & $0.322 \pm 0.06$ \\
LVEF, mean \pm SD & $86.09 \pm 134.2)$ \\
Repeat CABG, No. & 18.9 \\
Diabetes, No. & \\
Hemodialysis, No. & \\
COPD, No. & \\
\hline
\end{tabular}

$\mathrm{CABG}=$ coronary artery bypass grafting; $\quad \mathrm{COPD}=$ chronic obstructive pulmonary disease; LVEF $=$ left ventricular ejection fraction; LVESVI = left ventricular end-systolic volume index; $\mathrm{MI}=$ myocardial infarction; NYHA = New York Heart Association.

were the presence of left ventricular dysfunction (ejection fraction $[E F] \leq 0.40$ ), isolated $C A B G$, and no acute myocardial infarction during the month that preceded the operation. Exclusion criteria were prior cardiogenic shock, emergency surgery, off-pump CABG, implanta-

Table 2. Causes of Postoperative Death in the Study Subjects

\begin{tabular}{lc}
\hline Cause of Death & Patients, No. \\
\hline Immediate mortality rate (hospitalized patients) & \\
Low cardiac output & 1 \\
Myocardial infarction & 1 \\
Mediastinitis & 1 \\
8-year mortality rate & \\
Cardiac cause & \\
$\quad$ Sudden death & 2 \\
$\quad$ Massive pulmonary embolism & 1 \\
Noncardiac cause & \\
$\quad$ Cerebral hemorrhage & 1 \\
$\quad$ Cancer & 1 \\
Total & 8 \\
\hline
\end{tabular}

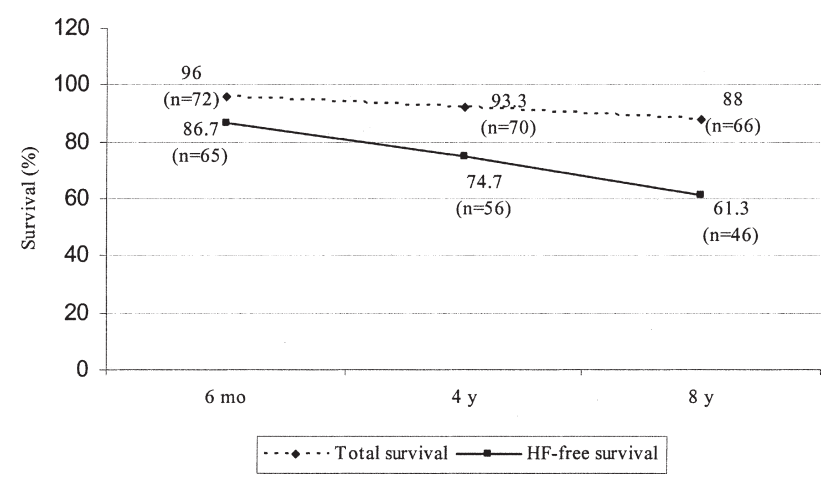

Fig 1. Total survival (dotted line) and freedom from heart failure (solid line) at the 4- and 8-year follow-up. (HF = heart failure.)

tion of an intraaortic balloon pump, combined valve procedures, or a left ventricular aneurysmectomy. The preoperative characteristics of the patients studied are summarized in Table 1.

\section{Preoperative Assessment}

All patients with ventricular dysfunction $(E F \leq 0.40$ on transthoracic-transesophageal echocardiography) and hibernating myocardium were studied preoperatively. The presence of this preserved myocyte functional activity was estimated by a transesophageal echocardiography stress test using dobutamine infusion according to dosages and infusion rates as previously described [10]. Hibernating myocardium was diagnosed if the patient had 5 or more reversible segments of the 16 myocardial segments [8], and 61 patients $(81.3 \%)$ had preoperative evidence of hibernating myocardium.

\section{Surgical Techniques}

All patients underwent isolated CABG using cardiopulmonary bypass. A similar operative technique was performed throughout the study. After sternotomy and harvesting of the left internal mammary artery, saphenous vein, or in selected cases, the radial artery, or both, cardiopulmonary bypass was initiated with normothermic perfusion. Cold St. Thomas crystalloid cardioplegia was intermittently given through the aortic root. Complete revascularization was achieved in all patients. The mean cardiopulmonary bypass time was $74 \pm 26$ minutes, and the mean ischemia time was $55 \pm 18$ minutes.

Table 3. Cardiac Events at Follow-Up

\begin{tabular}{lcc}
\hline Event & Patients, No. & Percentage \\
\hline CHF symptoms & 24 & 32 \\
Ventricular arrhythmia & 2 & 2.7 \\
Infarction & 5 & 6.7 \\
Reoperation & 0 & 0 \\
PCI & 3 & 4 \\
\hline
\end{tabular}

$\mathrm{CHF}=$ congestive heart failure; $\mathrm{PCI}=$ percutaneous coronary intervention. 


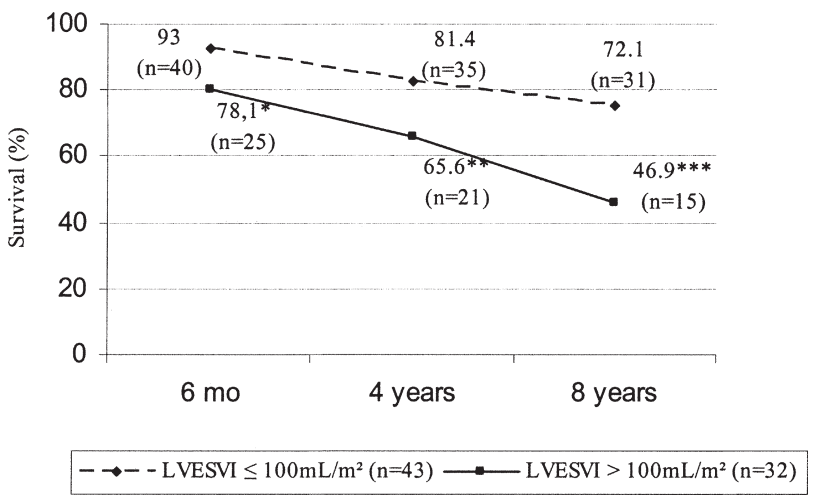

Fig 2. Freedom from heart failure in patients with a preoperative left ventricular end-systolic volume index (LVESVI) of $100 \mathrm{~mL} / \mathrm{m}^{2}$ or less (dashed line) and in those with an LVESVI exceeding 100 $\mathrm{mL} / \mathrm{m}^{2}$ (solid line). $\left({ }^{*} p<0.015 ;{ }^{* *} p<0.001 ;{ }^{* * *} p<0.001\right.$.)

\section{Postoperative Follow-Up}

The mean follow-up period was $8.1 \pm 0.6$ years. All survivors were clinically monitored in our outpatient department and underwent transthoracic echocardiography at 4 and 8 years postoperatively.

The clinical diagnosis of CHF was made if the patient had the following criteria (the first two criteria are essential):

- History of exertional dyspnea or orthopnea, or both.

- Clinical examination findings of bilateral basal crepitation on auscultation, bilateral pitting edema of the legs, and congested neck veins, with or without hepatomegaly.

- Clinical response to medical therapy.

\section{Statistical Analysis}

The values are presented as the mean \pm the standard deviation. Linear mixed models for repeated measures were performed to predict the postoperative trend of left ventricular function. The two-sample Student $t$ test was

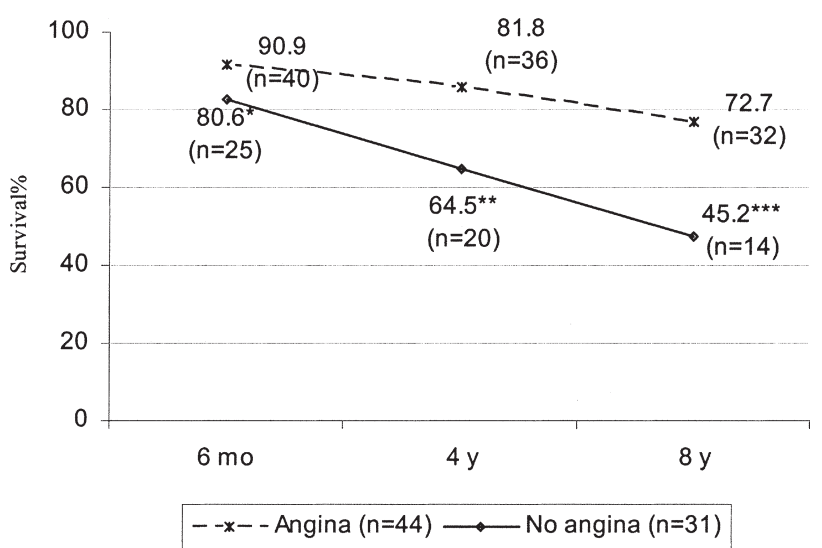

Fig 3. Long-term freedom from heart failure in patients with preoperative angina (dashed line) and those without (solid line). $\left({ }^{*} p<\right.$ $0.01 ;{ }^{* *} p<0.001 ;{ }^{* * *} p<0.001$.)

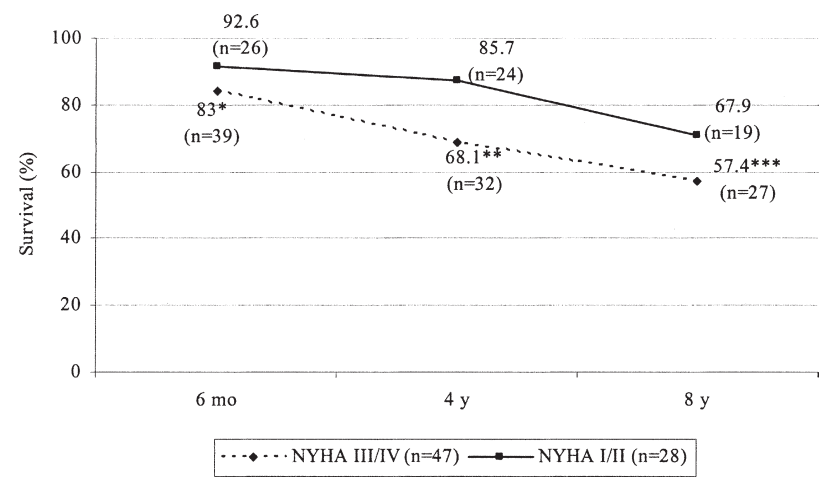

Fig 4. Long-term freedom from heart failure in patients at preoperative New York Heart Association (NYHA) functional class III/IV (dashed line) and those at NYHA I/II (solid line). $\left({ }^{*} p=0.18 ;{ }^{* *} p<\right.$ $0.001 ;{ }^{* * *} p=0.012$.)

used to test the impact of the individual preoperative variables on long-term CHF-free survival. Multivariate analysis was applied to determine the independent predictors of CHF-free survival. We have considered the following variables in the multivariate analysis: the presence of hibernating myocardium, presence of preoperative angina, the left ventricular ejection fraction (LVEF), the left ventricular end-systolic volume index (LVESVI), and the New York Heart Association (NYHA) functional class. Values of $p<0.05$ were considered statistically significant. Statistical analysis was performed with SPSS 15.0 software (SPSS Inc, Chicago, IL).

\section{Results}

Of the 75 patients enrolled in the study, 3 patients $(4 \%)$ died within 30 days of the operation. Five patients $(6.7 \%)$ died during follow-up, and the long-term total survival rate was $89.3 \%$. The causes of postoperative deaths are presented in Table 2. Only 1 patient, who emigrated, was lost to follow-up.

There was a statistically significant improvement in the LVEF during the short-term follow-up, defined as 6 months after the date of surgery, from $0.32 .2 \% \pm 6.0 \%$

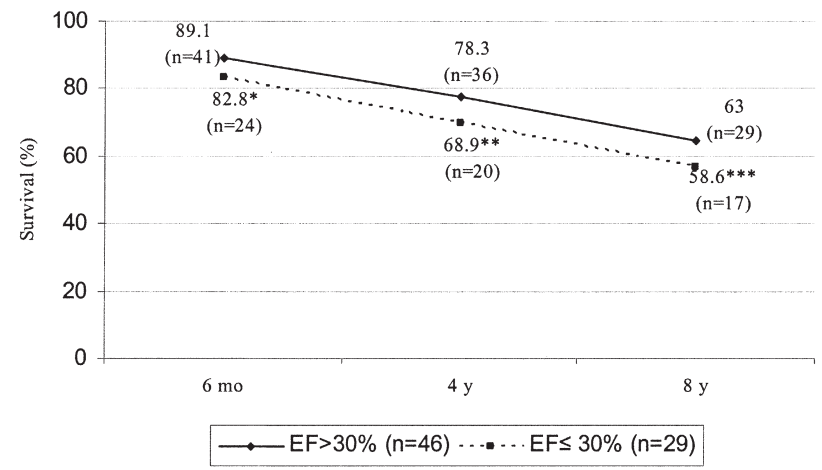

Fig 5. Long-term freedom from heart failure in patients with an preoperative ejection fraction (EF) exceeding 0.30 (solid line) and those at 0.30 or less (dashed line) $\left({ }^{*} p=0.17 ;{ }^{* *} p=0.12 ;{ }^{* * *} p=0.34\right.$ ). 


\section{Comment}

Survival at 8 Years

\begin{tabular}{lccccc}
\hline Variable & Coefficient & SE & OR & $95 \%$ CI & $p$ Value \\
\hline NYHA class & 0.78 & 0.36 & 1.2 & $2.12-6.67$ & $0.03^{\mathrm{a}}$ \\
Angina & 0.64 & 0.19 & 2.3 & $1.03-1.42$ & $0.03^{\mathrm{a}}$ \\
LVESVI & 0.32 & 0.15 & 0.998 & $0.997-0.999$ & $0.02^{\mathrm{a}}$ \\
EF & 0.004 & 0.003 & 0.996 & $0.991-1.011$ & 0.096 \\
Presence of & 0.794 & 0.590 & 0.995 & $0.990-0.132$ & 0.077 \\
$\quad$ HM & & & & & \\
\hline
\end{tabular}

${ }^{\text {a }}$ Statistically significant.

$\mathrm{CI}=$ confidence interval; $\quad \mathrm{EF}=$ ejection fraction; $\quad \mathrm{HM}=$ hibernat ing myocardium; LVESVI = left ventricular end-systolic volume index; $\quad$ NYHA $=$ New York Heart Association; $\mathrm{SE}=$ standard error; $\quad$ OR $=$ odds ratio.

to $44.0 \% \pm 4.0 \%(p=0.0001)$. However, the results of long-term follow-up showed that the postoperative LVEF did not differ with statistical significance from the immediate postoperative value (mean EF, $0.463 \pm 0.02, p=$ 0.12). There was no echocardiographic evidence of postoperative development of mitral regurgitation or worsening of preexisting mild mitral regurgitation in any patient.

Freedom from CHF was found in $74.7 \% \pm 6 \%$ of the patients 4 years after surgery and in $61.3 \% \pm 8 \%$ of the patients 8 years after surgery (Fig 1). When compared with the preoperative value, no statistically significant improvement in NYHA class was noted during long-term follow-up. Four years after CABG, the number of patients in NYHA class IV had decreased, with statistical significance, from a preoperative rate of $37.7 \%(n=28)$ to $24 \%$ $(\mathrm{n}=18)$ of the total population $(p<0.001)$. Eight years after the procedure, the number of patients in NYHA class IV significantly increased to 24 patients (32\%; $p<$ 0.02). All of these patients had preoperative symptoms of CHF.

Nine patients $(12 \%)$ who exhibited an immediate postoperative arrhythmia responded to medical therapy, with the exception of 1 patient who received an implantable cardiac defibrillator within 2 weeks postoperatively. A second patient required the implantation of an implantable cardiac defibrillator 3 years later because of an episode of ventricular tachycardia. Postoperative coronary angiography was performed in 14 patients $(18.7 \%)$ due to recurrence of symptoms. Percutaneous coronary intervention was performed in 3 patients because of an occluded venous graft. No repeat CABG was performed during the follow-up period. The cardiac events that occurred during long-term follow-up are in Table 3.

Multivariate regression analysis revealed a statistically significant correlation between CHF-free survival and an LVESVI of $100 \mathrm{~mL} / \mathrm{m}^{2}$ or less ( $p<0.001$; Fig 2$)$, symptoms of angina ( $p<0.001$; Fig 3$)$, and preoperative NYHA class $(p<0.01 ;$ Fig 4$)$. There was no statistically significant correlation between CHF-free survival and the preoperative value of the EF (Fig 5) or the presence of hibernating myocardium. The results of the multivariate analysis are in Table 4.
In this study, we showed that CABG in patients affected by depressed left ventricular function (LVEF $\leq 0.40$ ) confers a favorable but still not optimal long-term prognosis. We observed that surgical revascularization enhances left ventricular recovery and ensures long-term survival. Recurrent symptoms of CHF were not completely prevented, however; they developed primarily in patients with a limited functional capacity, those without preoperative symptoms of angina, and those with an extremely dilated ventricle $\left(\mathrm{eg}, \mathrm{LVESVI}>100 \mathrm{~mL} / \mathrm{m}^{2}\right)$.

\section{Assessment of Hibernating Myocardium and Patient Selection}

Predicting the likelihood of myocardial recovery and the postoperative prognosis in patients with depressed left ventricular function who underwent $C A B G$ remains a challenge [11]. Noninvasive tests that establish the presence and extent of hibernating myocardium are a requirement for accurate patient selection and a favorable postoperative result, but those tests are still being refined [12]. In our study, dobutamine stress echocardiography was performed preoperatively in all patients by the same cardiologist, and thallium-201 rest-redistribution scintigraphy was performed in $43(57 \%)$ patients. Both techniques are valuable in the identification of hibernating myocardium and in the prediction of a favorable postoperative outcome [13].

We confirmed in earlier research [9] that the preoperative presence of hibernating myocardium is a predictor of immediate postoperative improvement of left ventricular function in these patients. However, we found that hibernating myocardium had no predictive value with respect to long-term outcome. Freedom from heart failure was not statistically significantly correlated with the preoperative presence of hibernating myocardium.

The predictive role of the preoperative assessment of a viable myocardium has been confirmed by several authors $[8,14,15]$. Kron, commenting on the study by Chan and colleagues [8], noted that the problem of postoperative deterioration lies in patients who have no evidence of ischemia and hence do not benefit from revascularization. Elefteriades and colleagues [16] suggested that myocardial viability should be considered as a continuum "from full thickness viability without any scar to full thickness scarring without viable cells." To confirm this, preoperative viability studies (dobutamine stressechocardiography or thallium) should be correlated with the histologic results of biopsied cardiac tissue.

\section{Patient Survival}

Data on the long-term results of CABG in patients with impaired left ventricular function are few [13, 17]; therefore, we conducted this prospective study of selected patients with compromised left ventricular function. Eight years after $C A B G, 89.3 \%$ of the patients in our series were alive. CHF-free survival after CABG was $74.7 \%$ at 4 years and $61.3 \%$ at 8 years (an outcome better than that of previous series) [7]. However, those studies 
included patients without established hibernating myocardium at the preoperative assessment [7]. A surprising finding was that the presence of hibernating myocardium was not a statistically significant predictor of long-term survival in our patients. Hibernating myocardium may have more greatly affected the immediate postoperative outcome than the long-term outcome, a theory supported by the fact that an immediate postoperative improvement in left ventricular function indicators was not followed by a further improvement in late follow-up.

\section{Recovery of Left Ventricular Function and Recurrence of Heart Failure}

Our data showed a substantial improvement in left ventricular function after revascularization. However, when we compared the recovery of left ventricular function in long-term follow-up with immediate postoperative improvement, we noted no statistically significant change. Shivalkar and colleagues [18] showed that the myocardial structure of the hypocontractile segments has a critical role in functional recovery. The extent of hibernating myocardium appears to be a positive predictor of left ventricular functional improvement after $C A B G$. The presence of a well-developed coronary collateral net has also been shown to predict the resumption of segmental wall motion [19].

Revascularization reduces postoperative mortality and morbidity in these patients but does not protect against the progression of ischemic cardiomyopathy in some of them. The time-limited beneficial effects of revascularization in patients with left ventricular dysfunction have also been shown by Luciani and colleagues [20], who noted that $47 \%$ of the patients studied were free of the symptoms of heart failure 5 years after CABG, despite an absolute survival rate of $75 \%$ for that time period. In their series, only $48 \%$ of the patients had undergone a preoperative assessment of myocardial viability; this rendered the need for CABG in patients with irreversible myocardial damage likely. Further homogenous clinical series are needed to further elucidate the optimal patient selection for the treatment of ischemic cardiomyopathy.

\section{Predictors of Late Outcome}

In our series, preoperative symptoms of ischemia and CHF appeared to be the most statistically significant predictors of long-term outcome. Our finding supports the observation of Lansman and colleagues [21], who stated that the presence of angina predicted a good survival rate and a consistent improvement in left ventricular function. However, other investigators [13] have shown that the presence of angina had no statistically significant predictive value with regard to long-term mortality and the recurrence of heart failure.

Dreyfus and colleagues [22] emphasized the importance of using viability tests instead of clinical evaluation as a crucial determinant of patient selection and subsequent postoperative outcome. In our series, hibernating myocardium was a statistically significant predictor of immediate postoperative recovery, but the preoperative ischemia class and NYHA functional class were statistically significant predictors of long-term outcome.

The LVESVI proved to be an important predictor of both short- and long-term functional improvement in our series. In patients who had a preoperative LVESVI of 100 $\mathrm{mL} / \mathrm{m}^{2}$ or less, we observed a favorable outcome for survival and the recovery of left ventricular function. That finding supports the conclusion of other investigators $[23,24]$ who noted that the LVESVI was the only independent measurement that was predictive of survival and the improvement of left ventricular function. The LVESVI is a simple and noninvasive preoperative predictor of postoperative functional recovery. It can be solely used in the decision making in patients with ischemic cardiomyopathy; however, further studies with larger groups of patients are needed to confirm this statement. On the other hand, the EF value was not a statistically significant predictor of long-term outcome in our series. Like other authors [25], we observed that the $\mathrm{EF}$ was not a strong predictor of outcome in patients with severe left ventricular dysfunction. That theory rests on the fact that a low EF did not differentiate between hibernation and infarction as the cause of poor contractile function.

In conclusion, we found that revascularization conferred a low postoperative mortality rate and a potential benefit to left ventricular function in patients with impaired left ventricular function. The long-term survival rate in our series was better than that in previous series. We found that long-term freedom from heart failure could be predicted by the preoperative presence of angina and a preoperative LVESVI of $100 \mathrm{~mL} / \mathrm{m}^{2}$ or less. The presence of preoperative NYHA class III or IV was a predictor of a less favorable long-term outcome.

\section{References}

1. Ascione R, Narayan P, Rogers CA, Lim KH, Capoun R, Angelini GD. Early and midterm clinical outcome in patients with severe left ventricular dysfunction undergoing coronary artery surgery. Ann Thorac Surg 2003;76:793-9.

2. Milano CA, White WD, Smith LR, et al. Coronary artery bypass in patients with severely depressed ventricular function. Ann Thorac Surg 1993;56:487-93.

3. Ferguson TB Jr, Hammill BG, Peterson ED, DeLong ER, Grover FL; STS National Database Committee. A decade of change-risk profiles and outcomes for isolated coronary artery bypass grafting procedures, 1990-1999: a report from the STS National Database Committee and the Duke Clinical Research Institute. Society of Thoracic Surgeons. Ann Thorac Surg 2002;73:480-489; discussion 489-90.

4. Yau TM, Fedak PW, Weisel RD, Teng C, Ivanov J. Predictors of operative risk for coronary bypass operations in patients with left ventricular dysfunction. J Thorac Cardiovasc Surg 1999;118:1006-13.

5. Davierwala PM, Maganti M, Yau TM. Decreasing significance of left ventricular dysfunction and reoperative surgery in predicting coronary artery bypass grafting-associated mortality: a twelve-year study. J Thorac Cardiovasc Surg 2003;126:1335-44.

6. Cimochowski GE, Harostock MD, Foldes PJ. Minimal operative mortality in patients undergoing coronary artery bypass with significant left ventricular dysfunction by maximi- 
zation of metabolic and mechanical support. J Thorac Cardiovasc Surg 1997;113:655-64; discussion 664-6.

7. Appoo J, Norris C, Merali S, et al. Long-term outcome of isolated coronary artery bypass surgery in patients with severe left ventricular dysfunction. Circulation 2004;110: II13-II27.

8. Chan RK, Raman J, Lee KJ, et al. Prediction of outcome after revascularization in patients with poor left ventricular function. Ann Thorac Surg 1996;61:1428-34.

9. Soliman Hamad MA, Peels K, Van Straten A, Van Zundert A, Schonberger J. Coronary artery bypass surgery in patients with impaired left ventricular function. Predictors of hospital outcome. Acta Anaesthesiol Belg 2007;58:37-44.

10. La Canna G, Alfieri O, Giubbini R, Gargano M, Ferrari R, Visioli $\mathrm{O}$. Echocardiography during infusion of dobutamine for identification of reversibly dysfunction in patients with chronic coronary artery disease. J Am Coll Cardiol 1994;23: 617-26.

11. Dilsizian V, Bonow RO. Current diagnostic techniques of assessing myocardial viability in patients with hibernating and stunned myocardium. Circulation 1993;87:1-20; erratum, Circulation 1993;87:2070.

12. La Canna G, Rahimtoola SH, Visioli O, et al. Sensitivity, specificity, and predictive accuracies of non-invasive tests, singly and in combination, for diagnosis of hibernating myocardium. Eur Heart J 2000;21:1358-67.

13. Lorusso R, La Canna G, Ceconi C, et al. Long-term results of coronary artery bypass grafting procedure in the presence of left ventricular dysfunction and hibernating myocardium. Eur J Cardiothorac Surg 2001;20:937-48.

14. Elefteriades JA, Tolis G Jr, Levi E, Mills LK, Zaret BL. Coronary artery bypass grafting in severe left ventricular dysfunction: excellent survival with improved ejection fraction and functional state. J Am Coll Cardiol 1993;22:1411-7.

15. Tan J, Kejriwal N, Vasudevan A, Maria PL, Alvarez JM. Coronary bypass surgery for patients with chronic poor preoperative left ventricular function $(\mathrm{EF}<30 \%)$ : 5-year follow-up. Heart Lung Circ 2006;15:130-6.

16. Samady H, Elefteriades JA, Abbott BG, Mattera JA, McPherson CA, Wackers FJ. Failure to improve left ventricular function after coronary revascularization for ischemic cardiomyopathy is not associated with worse outcome. Circulation 1999;100:1298-304.

17. Gunning MG, Chua TP, Harrington D, et al. Hibernating myocardium: clinical and functional response to revascularisation. Eur J Cardiothorac Surg 1997;11:1105-12.

18. Shivalkar B, Maes A, Borgers M, et al. Only hibernating myocardium invariably shows early recovery after coronary revascularization. Circulation 1996;94:308-15.

19. Kozman H, Cook JR, Wiseman AH, Dann RH, Engelman RM. Presence of angiographic coronary collaterals predicts myocardial recovery after coronary bypass surgery in patients with severe left ventricular dysfunction. Circulation 1998;98:II57-61.

20. Luciani GB, Montalbano G, Casali G, Mazzucco A. Predicting long-term functional results after myocardial revascularization in ischemic cardiomyopathy. J Thorac Cardiovasc Surg 2000;120:478-89.

21. Lansman SL, Cohen M, Galla JD, et al. Coronary bypass with ejection fraction of 0.20 or less using centigrade cardioplegia: long-term follow-up. Ann Thorac Surg 1993;56:480-485; discussion $485-6$.

22. Dreyfus GD, Duboc D, Blasco A, et al. Myocardial viability assessment in ischemic cardiomyopathy: benefits of coronary revascularization. Ann Thorac Surg 1994;57:1402-7; discussion 1407-8.

23. Hamer AW, Takayama M, Abraham KA, et al. End-systolic volume and long-term survival after coronary artery bypass graft surgery in patients with impaired left ventricular function. Circulation 1994;90:2899-904.

24. Yamaguchi A, Ino T, Adachi $\mathrm{H}$, Mizuhara A, Murata S, Kamio H. Left ventricular end-systolic volume index in patients with ischemic cardiomyopathy predicts postoperative ventricular function. Ann Thorac Surg 1995;60:1059-62.

25. Langenburg SE, Buchanan SA, Blackbourne LH, et al. Predicting survival after coronary revascularization for ischemic cardiomyopathy. Ann Thorac Surg 1995;60:1193-6; discussion 1196-7. 